planned by the University of Paris. It was to be housed in part of the hotel de la Rochefoucauld d'Estissac; this, however, has been bought by the "Maison de la Chimie" (see Nature, June 11, p. $865)$ for three million francs, which will be used by the "Foyer International Universitaire" to acquire another building in rue de la Four (the former École de Bouffémont). "Le Cercle Universitaire International" is a club projected by the Associations of University Students to receive visiting colleagues and university men and to organise meetings and lectures that will promote international friendship. Its president is M. Paul Langevin, and its temporary address is at the Musée Pédagogique, 41 rue Gay-Lussac, Paris.

\section{Institut International de Documentation}

THE eleventh Conference of the Institut International de Documentation (formerly de Bibliographie) will be held this year at Frankfort-on-Main on Aug. 30Sept. 3. The Conference is open to all persons interested in the various aspects of documentation, that is, the collection, arrangement, filing, and indexing of graphic records. As in previous years, an attractive programme of papers has been arranged for presentation and discussion during the mornings, whilst the afternoons and evenings will be devoted to visits of inspection and recreation. The latter include visits to Darmstadt and Mainz, where State and municipal libraries will be inspected. The Conference fee of 12 R.M. includes all excursions. A special exhibition of technical appliances for library purposes (Adrema machines, photocopying apparatus, duplicating machines, metal furniture, etc.) has been organised in a room of the Conference building during the meeting. The programme of papers to be presented is not yet available, but copies of all papers will be distributed to members of the Conference prior to the opening session. Full particulars regarding hotels and accommodation and further details of the Conference may be obtained from the organising secretary, Dr. Schürmeyer, Direktor der Bibliothek für Kunst und Technik, Frankfurt am Main, or from the Secretary, British Society for International Bibliography, Science Library, South Kensington, S.W.7.

\section{Sotheran's "Bibliotheca Chemico-Mathematica"}

Messrs. Sotheran, Ltd., have issued a first supplement to their "Bibliotheca Chemico-Mathematica" which was published in two volumes in 1921, and have again laid all students of science and technology under a debt of gratitude. The work pretends to be no more than a bookseller's catalogue, and does not, therefore, aim at completeness, but in fact it contains a most representative list of works, to the number of more than seven thousand items, of old writers in all branches of science, and a number of standard modern works. It is rendered of permanent reference value by the fact that the title-pages in the majority of cases are transcribed in full, and by the unusual wealth and scope of the notes that accompany most of the entries. One of the most interesting items (presumably to be sold as a whole) is a collection of more than eight hundred books from Newton's library, including copies of the first and second editions of the "Principia" with corrections, cancellations, and additions in Newton's handwriting-many of which were not incorporated in the later editions and would thus be of the utmost interest as showing the progress of Newton's thought--an annotated copy of Euclid, and many other works with Newton's autograph.

THe catalogue also includes a few books that belonged to Faraday and were bound and annotated by him, original copies of the first edition of Galileo's "Dialogo", a complete set of the Paris Academy's "Description des arts et métiers", with all its supplements, which is very rarely seen in the sale room-or the library-in its complete form, and, especially noteworthy, a copy of William Gilbert's "De Mag. nete ", 1600, inscribed in what appears undoubtedly to be the autograph of the author, of which no other universally accepted example is known. The annotations are trustworthy and of great interest, and will save a great deal of searching through scattered authorities, the latest of whom appear to have been consulted. It is good to see that the title 'Honourable' is no longer given to Henry Cavendish, and it is to be hoped that Messrs. Sotheran's correction will finally destroy this persistent delusion. Prices appear to have risen since the date of the original catalogues, but remain moderate. Booksellers' catalogues are usually looked through rapidly for desired acquisitions, and if kept at all, are cut up for filing purposes, but the present volume is a bibliographical tool of value and should take its place beside its predecessors on the library shelf. It and the volumes still to come form a worthy memorial to the late H. C. Sotheran, to whom the volume is dedicated.

\section{A New Periodical on Acoustics}

THE rapid development of acoustics since the production of the thermionic valve is accompanied by so large an increase in the bulk of research papers that for some time the Acoustical Society of America has been publishing its own Journal devoted to the subject. A French journal, Revue d'Acoustique, is now to be published bi-monthly under the direction of a committee of well-known authorities. The first number, dated March 1932, wisely opens with a vocabulary, founded on that of the Committee on Acoustical Standardisation ( $J$. Acoustical Soc. of Am., 2, No. 3), of acoustical terms with definitions and English equivalents, and authors are asked to indicate when they use a term with a different meaning. In addition to papers, abstracts longer than those usually available in Science Abstracts and a bibliography of papers and books published since 1925 are given. This latter section is classified under physiological acoustics, acoustic measurements, propagation, sound sources, sound receivers, music, mechanical music, noise and architectural acoustics, and books and general articles. The titles are given in French, with some inconsistencies of translation. Although a journal of acoustics will naturally be used

No. 3275 , VoL. 130 